\title{
Assessment of analgesic and antipyretic activity of traditional formula used in the treatment of seasonal infections
}

\author{
*Kugalur Ganesan Parthiban¹, Senthil Kumar Natesan², Ganesan Sekar², Krishnamoorthi Mahalakshm \\ ${ }^{1}$ Department of Pharmacy, Prist University, Tanjore, Tamil Nadu, India \\ ${ }^{2}$ Department of Pharmaceutics, JKKMMRF College of Pharmacy, Komarapalayam, Namakkal, Tamil Nadu, India
}

\begin{abstract}
Traditional treatments and medicines are the main sometimes the only source of health care for millions of people living in rural areas of developing countries. The aim of the present study is to investigate the analgesic and antipyretic activity of individual plant extracts and poly-herbal formula $[\mathrm{PHF}]$ made in to liquid dosage form of three different doses in albino rats. The plant materials were extracted in boiling distilled water for six hours, filtered, concentrated and dried. The aqueous extracts were prepared in to poly-herbal liquid dosage form by using water, glycerol mixture and acacia $2 \%$ in three different preparation of varying extract doses. $1 \mathrm{ml}$ of above preparations orally fed for investigation. Pentozocine and paracetamol was used as standard drugs respectively. For individual plants the extracts were suspended in $2 \%$ acacia solution and performed. The results of analgesic and anti-pyretic activity of PHF 1 and PHF 2 showed significant results $(\mathrm{P}<0.01$ and $\mathrm{P}<0.05$ respectively) and PHF3 did not show any significant results. In the individual plant extracts slightly significant activity $(\mathrm{P}<0.05)$ was observed.
\end{abstract}

Key Words: Traditional medicine, poly-herbal, formula, extract, glycerol, aqueous.

\section{INTRODUCTION}

Traditional medicines is the sum of total knowledge, skills and practices based on the theories, beliefs, and experiences indigenous to different cultures that are used to maintain health, as well as to prevent, diagnose, improve or treat physical and mental illness (WHO, 2008). Traditional medicines have been used in some communities for thousands of years. As traditional medicine practices are adopted by new population there are challenges.

Traditional medicine practices have been adopted on different culture region without the parallel advance of international standards and method for evaluation. Scientific evidence from tests done to evaluate safety and effectiveness of traditional medicine, products and practices is limited while evidence shows that some herbal medicines are effective for specific conditions, further study of products and practices is needed. Requirements and methods for assessment and evaluation are complex. The safety effectiveness and quality of finished herbal medicine product depend on the quality of their source materials (which can include hundreds of natural constituents) and how elements are handled through production processes. For many millions of people, often living in rural areas of developing countries herbal medicines, traditional treatments and traditional practitioners are the main, sometimes the only source of healthcare (WHO, 2008).

This poly-herbal formula is used by Valayar tribal community of kundry hill area erode district, Tamilnadu, India for the treatment of seasonal infections. This formula consists of Andrographis paniculata (Acanthaceae), Cardiospermum halicacabum (Sapindaceae) Evolulus alsinodes (Convolvulaceae), Cynodon dactylon (Poaceae)

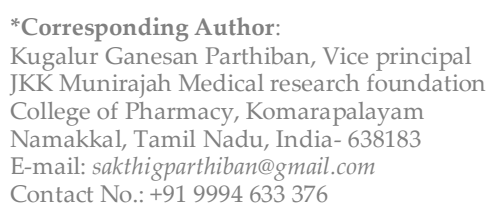

and Phyllanthus emblica fruit (Phyllanthaceae). Aim of the presence study was to investigate the potency of analgesic and anti-pyretic activity of the poly-herbal formula made into a liquid dosage form in three different doses.

\section{MATERIALS AND METHODS}

Plant materials were collected for our work from and around of Bhavani, Erode, Trichi and Thiruchengodu areas of Tamilnadu, India. The plants Andrographis paniculata (Acanthaceae), Cardiospermum halicacabum (Sapindaceae), Evolulus alsinodes (Convolvulaceae), Cynodon dactylon (Poaceae) and Phyllanthus emblica fruit (Phyllanthaceae) were identified by the botanical survey of India, Tamilnadu, Coimbatore. Voucher specimen has been preserved (Ref. no. BSI/SRC/5/23/2010-11/Thec. 1813, $8,9,12 \& 7$, dated 03.02.2011). The above plants hereafter designated as plant $1,2,3,4,5$ as per above order.

\section{Collections}

The plants were collected by digging the entire plant, cutting and separating the roots from the whole part of the plant. Phyllanthus emblica fruit has been collected from kundery hills.

\section{Treatment}

The aerial parts were cut into small pieces by means of stainless steel knife and put on polythene sheet and shade dried. Phyllanthus emblica fruit was shade dried and the seeds were removed. The dried material was powdered by means of wood grinder.

\section{Preparation of extracts}

The coarse powders of $150 \mathrm{gm}$ plant material are first macerated for overnight and each were boiled in distilled water for 6 hours separately. It was filtered while hot and concentrated. The resulting extract was dried, percentage yield was noted and kept in a desiccators. The above dried extracts were used to prepare liquid dosage form and pharmacological studies (Cooper and Gunn, 1986). 
Table 1: Formula for liquid dosage form.

\begin{tabular}{cccc}
\hline \multirow{2}{*}{ Aqueous Extracts } & \multicolumn{3}{c}{ Poly herbal liquid dosage form } \\
\cline { 2 - 4 } & $\mathbf{1}$ & $\mathbf{2}$ & $\mathbf{3}$ \\
\hline Andrographis paniculata & $87.5 \mathrm{mg}$ & $43.75 \mathrm{mg}$ & $21.87 \mathrm{mg}$ \\
$\begin{array}{c}500 \mathrm{mg} / \mathrm{kg} \\
\text { Cardiospermum }\end{array}$ & $87.5 \mathrm{mg}$ & $43.75 \mathrm{mg}$ & $21.87 \mathrm{mg}$ \\
$\begin{array}{c}\text { halicacabum } 500 \mathrm{mg} / \mathrm{kg} \\
\text { Evolulus alsinodes }\end{array}$ & $87.5 \mathrm{mg}$ & $43.75 \mathrm{mg}$ & $21.87 \mathrm{mg}$ \\
$\quad \begin{array}{c}500 \mathrm{mg} / \mathrm{kg} \\
\text { Cynodon dactylon } \\
\quad \text { 600mg/kg }\end{array}$ & $105 \mathrm{mg}$ & $52.5 \mathrm{mg}$ & $26.35 \mathrm{mg}$ \\
$\begin{array}{c}\text { Phyllanthus emblica } \\
\text { 600mg } / \mathrm{kg}\end{array}$ & $105 \mathrm{mg}$ & $52.5 \mathrm{mg}$ & $26.35 \mathrm{mg}$ \\
\hline
\end{tabular}

Table 2: Analgesic activity of liquid dosage form.

\begin{tabular}{llllll}
\hline Groups & $\mathbf{0 ~} \mathbf{~ m i n}$ & $\mathbf{3 0} \mathbf{~}$ in & $\mathbf{6 0} \mathbf{~ m i n}$ & $\mathbf{9 0} \mathbf{~ m i n}$ & $\mathbf{1 2 0} \mathbf{~ m i n}$ \\
\hline Control & $3.16 \pm 0.30$ & $3.33 \pm 0.33$ & $3.0 \pm 0.36$ & $3.50 \pm 0.22$ & $3.33 \pm 0.21$ \\
Standard & $3.33 \pm 0.21$ & $6.83 \pm 0.30^{* *}$ & $7.83 \pm 0.30^{* *}$ & $8.0 \pm 0.36^{* *}$ & $7.50 \pm 0.50^{* *}$ \\
LDF-1 & $3.33 \pm 0.33$ & $5.00 \pm 0.36^{* *}$ & $7.16 \pm 0.60^{* *}$ & $7.83 \pm 0.47^{* *}$ & $6.16 \pm 0.30^{* *}$ \\
LDF-2 & $3.50 \pm 0.42$ & $4.83 \pm 0.30^{*}$ & $4.50 \pm 0.22^{*}$ & $4.83 \pm 0.16^{*}$ & $4.66 \pm 0.21^{*}$ \\
LDF-3 & $3.66 \pm 0.42$ & $4.16 \pm 0.30$ & $4.33 \pm 0.21$ & $4.66 \pm 0.33$ & $4.33 \pm 0.21$ \\
\hline Values are mean $\pm S . E . M ; n=6 ; \mathrm{LDF}=$ Liquid dosage form & & \\
${ }^{*} \mathrm{P}<0.05$ and ${ }^{* *} \mathrm{P}<0.01 ;$ as compared to the control &
\end{tabular}

Preparation of poly-herbal liquid dosage form

All the weighed quantities of dried extracts has been mixed in water glycerol 70:30 mixture, and stirred at 3000 rpm using Remi high speed mixture for 1 hour along with acacia $2 \%$ as suspending agent. Sodium benzoate $0.5 \%$ was used as preservative (Mukesh, 2007). Table 1 shows doses for plant extracts 1, 2, 3, 4, 5 that were determined following previously published literatures (Shivaprakash et al., 2011; Datta et al., 2010; Lekshmi and Reddy, 2011; Garg and Paliwal, 2011; Jaijoy et al., 2010).

\section{Experimental animals}

Wistar albino rats weigh about $160-175$ gms of either sex were procured from Govt. Veterinary College, Trishur, Mannuthi, Kerala. Rats were placed in polypropylene cages in a controlled room temperature $22 \pm 1^{\circ} \mathrm{C}$ and relative humidity of $60-70 \%$ in registered animal house (87/1999/CPCSEA). They were maintained with standard pellet diet (Amrut brand sangle, India) and water ad libitum. Animal were acclimatized to laboratory condition for seven days before commencement of any experiment. Ethical clearance was obtained from institutional animal ethical committee.

\section{Chemicals and reagents}

The standard drug for analgesic activity is pentazocine and for anti-pyretic effect activity paracetamol is used. All the other chemical and reagents were of pure analytical grade and obtained from local supplier.

\section{Acute oral toxicity}

The acute oral toxicity was carried out as per OECD 423guidelines (Acute toxic class method) for both formulations and individual plant extracts. The acute toxicity studies revealed that there is no toxicity signs are produced up to the dose level $2000 \mathrm{mg} / \mathrm{kg}$.

\section{Assessment of analgesic activity Eddy's hot plate method}

Albino rats were divided into five different groups of six animals each. Test groups were fed orally with $1 \mathrm{ml}$ poly herbal liquid dosage form F1, F2, and F3, respectively. The hot plate was maintained at $55 \pm 0.5^{\circ} \mathrm{C}$ and the animals were placed into the Perspex cylinder on the heated
Table 3: Analgesic activity of individual plants.

\begin{tabular}{|c|c|c|c|c|c|}
\hline Groups & $0 \mathrm{~min}$ & $30 \mathrm{~min}$ & $60 \mathrm{~min}$ & $90 \mathrm{~min}$ & $120 \mathrm{~min}$ \\
\hline Control & $3.00 \pm 0.36$ & $3.00 \pm 0.36$ & $3.33 \pm 0.33$ & $3.33 \pm 0.33$ & $3.33 \pm 0.21$ \\
\hline Standard & $3.33 \pm 0.31$ & $6.00 \pm 0.51^{* *}$ & $7.00 \pm 0.44^{* *}$ & $7.66 \pm 0.42^{* *}$ & $7.00 \pm 0.36^{* *}$ \\
\hline Plant 1 & $3.50 \pm 0.22$ & $4.33 \pm 0.21^{*}$ & $4.83 \pm 0.30^{*}$ & $5.16 \pm 0.40^{*}$ & $4.66 \pm 0.33^{*}$ \\
\hline Plant 2 & $3.16 \pm 0.30$ & $4.50 \pm 0.22^{*}$ & $4.66 \pm 0.21^{*}$ & $4.83 \pm 0.30^{*}$ & $4.50 \pm 0.34^{*}$ \\
\hline Plant 3 & $3.50 \pm 0.22$ & $4.00 \pm 0.36$ & $4.16 \pm 0.30^{*}$ & $4.66 \pm 0.42$ & $4.33 \pm 0.33$ \\
\hline Plant 4 & $3.00 \pm 0.36$ & $3.83 \pm 0.30$ & $3.83 \pm 0.33$ & $4.00 \pm 0.36$ & $3.83 \pm 0.40$ \\
\hline Plant 5 & $3.00 \pm 0.36$ & $3.66 \pm 0.21$ & $3.83 \pm 0.33$ & $4.33 \pm 0.33$ & $4.16 \pm 0.30$ \\
\hline
\end{tabular}

surface and time to discomfort reaction like licking paws or jumping was recorded as response latency by using a stop watch. The latency was recorded (Mahesh et al., 2009 ), after $0 \mathrm{~min}, 30 \mathrm{~min}, 60 \mathrm{~min}, 90 \mathrm{~min}, 120 \mathrm{~min}$, after the administration of test and standard drug. The standard drug used was pentazocine at a dose of $10 \mathrm{mg} / \mathrm{kg}$.

\section{Individual plants}

Rats were divided in to seven groups of six animals each. Test groups were fed orally with $1 \mathrm{ml}$ of plant extracts in acacia suspension. The latency was recorded after $0 \mathrm{~min}$, $30 \mathrm{~min}, 60 \mathrm{~min}, 90 \mathrm{~min}, 120 \mathrm{~min}$, after the administration of test and standard drug.

\section{Assessment of anti-pyretic activity \\ Brewer's yeast induced pyrexia model}

Anti-pyretic activity was measured by slightly modifying the method described with Albino rats by Venkatesh et al. (2012). Before the experiments, for 18 hours, pyrexia was induced by subcutaneously injecting $10 \mathrm{ml} / \mathrm{kg}$ brewer's yeast into the animals' dorsum region. 19 hour after the injection, the rectal temperature of each rat was measured by digital thermometer. Only rats showing an increase in temperature of at least $0.7^{\circ} \mathrm{C}$ were used for experiment. Doses of poly herbal liquid dosage form F1, F2, F3 and individual plant extracts were administered orally and temperatures were measured at 1, 2, 3 and 4 hours after administration.

\section{Individual plants}

Rats were divided in to seven groups of six animals each. Test groups were fed orally with $1 \mathrm{ml}$ of plant extracts in acacia suspension. The body temperature was recorded after 1, 2, 3 and 4 hours after the administration of test and standard drug.

\section{RESULTS AND DISCUSSION}

Analgesic activity

PHF 1 and PHF 2 significantly $(\mathrm{P}<0.01$ and $\mathrm{P}<0.05$ respectively) elevated the mean basal reaction time as compared to control group. The highest nociception inhibition was exhibited by PHF 1 at 30,60, 90, and 120 minutes but PHF 2 produces slightly significant $(\mathrm{P}<0.05)$ effect at the same time intervals so that the activity is in dose dependent manner. While the individual plant extracts 1 and 2 exhibits slightly significant analgesic activity $(\mathrm{P}<0.05)$ at $30,60,90$, and 120 minutes. Plant extract 3 shows significant activity $(P<0.05)$ only at 60 minutes.

The maximum nociception inhibition by pentazocine ( $\mathrm{P}$ $<0.01$ ) as a standard drug was observed at 30,60,90 and 120 minutes. PHF 3 and individual drugs 4 and 5 did not produce any significant nociception inhibition as compared to control group. The observations are given in Table $2 \& 3$ and Figure $1 \& 2$ 


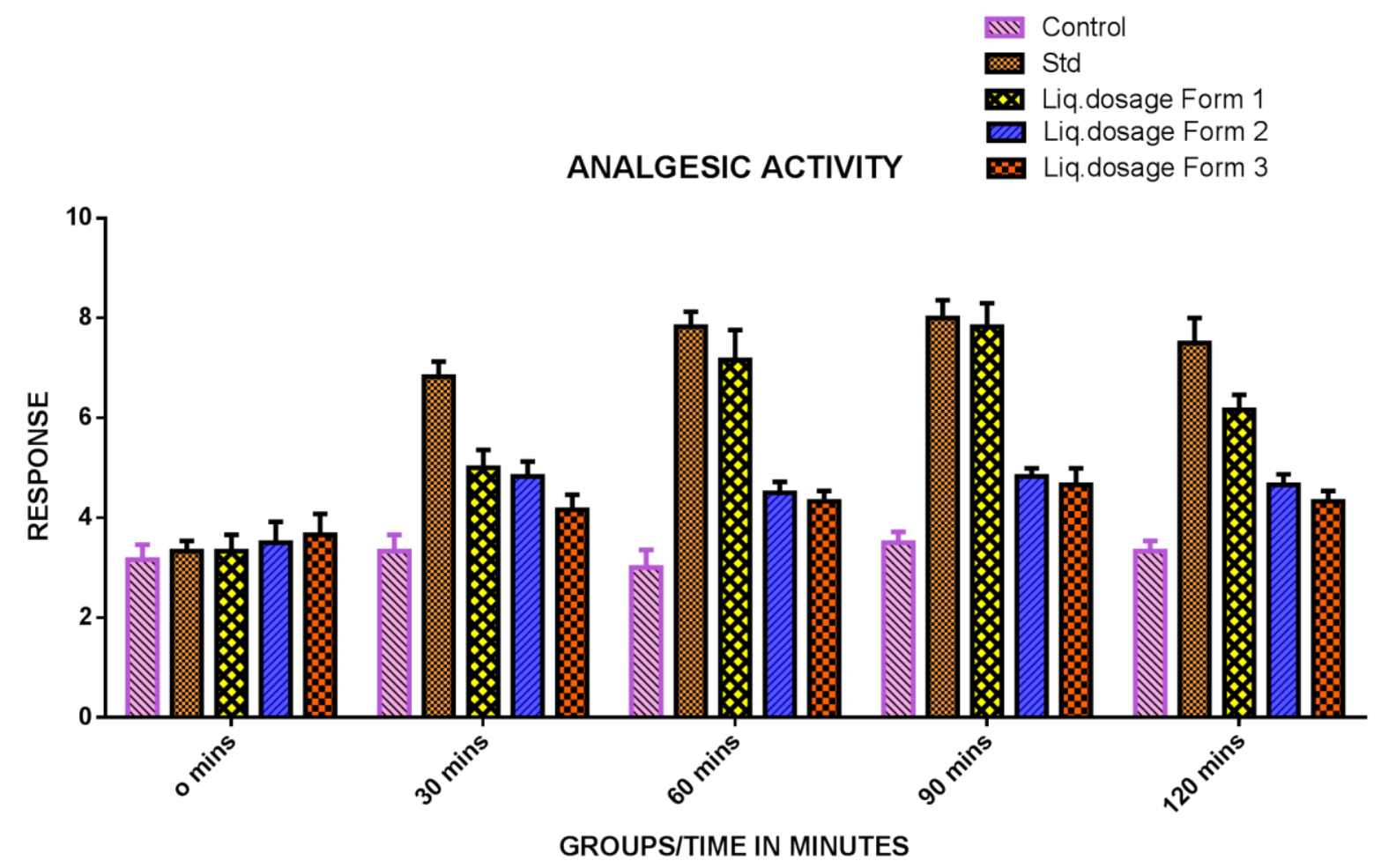

Figure 1: Analgesic activity of liquid dosage form.

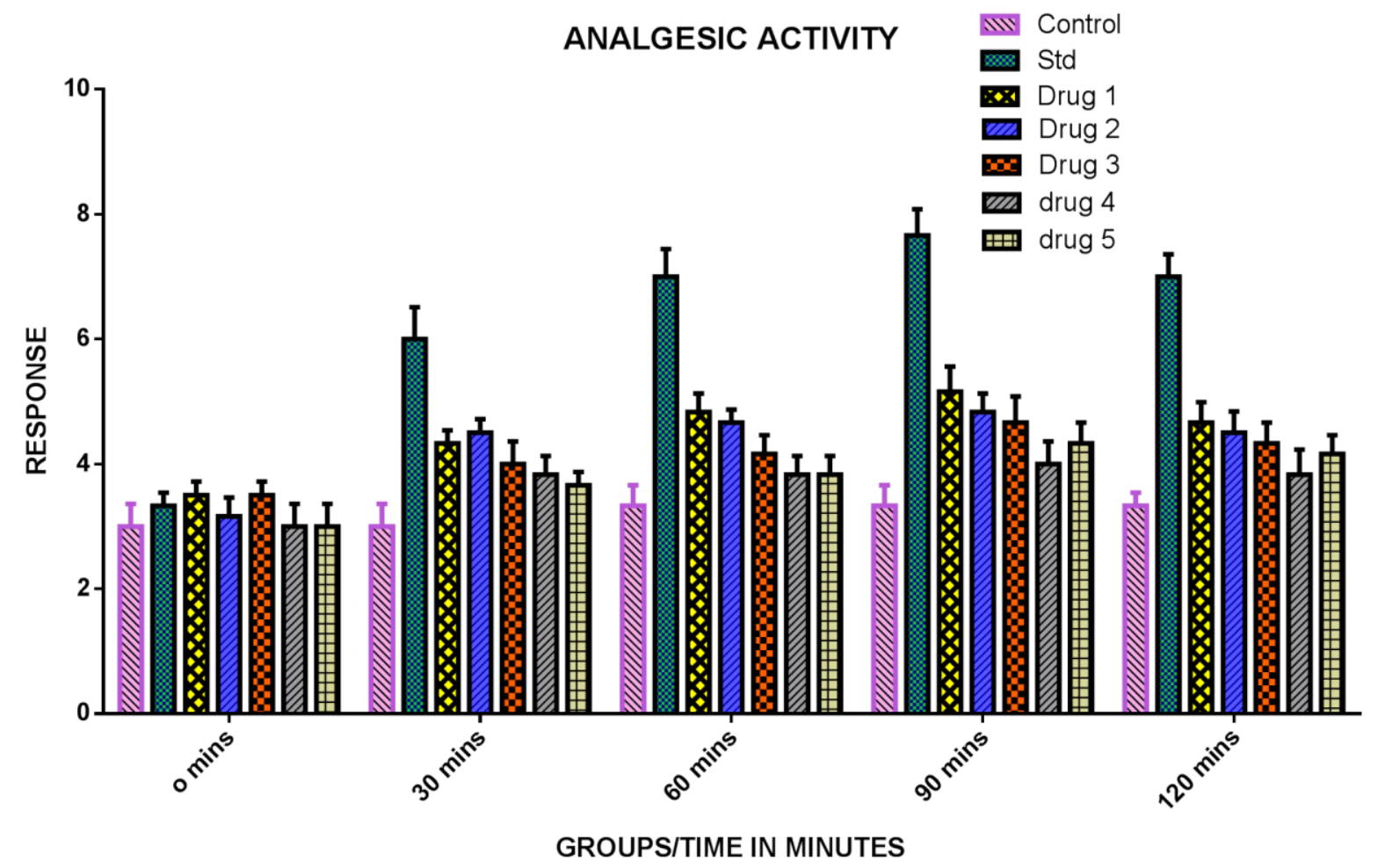

Figure 2: Analgesic activity of individual plants. 


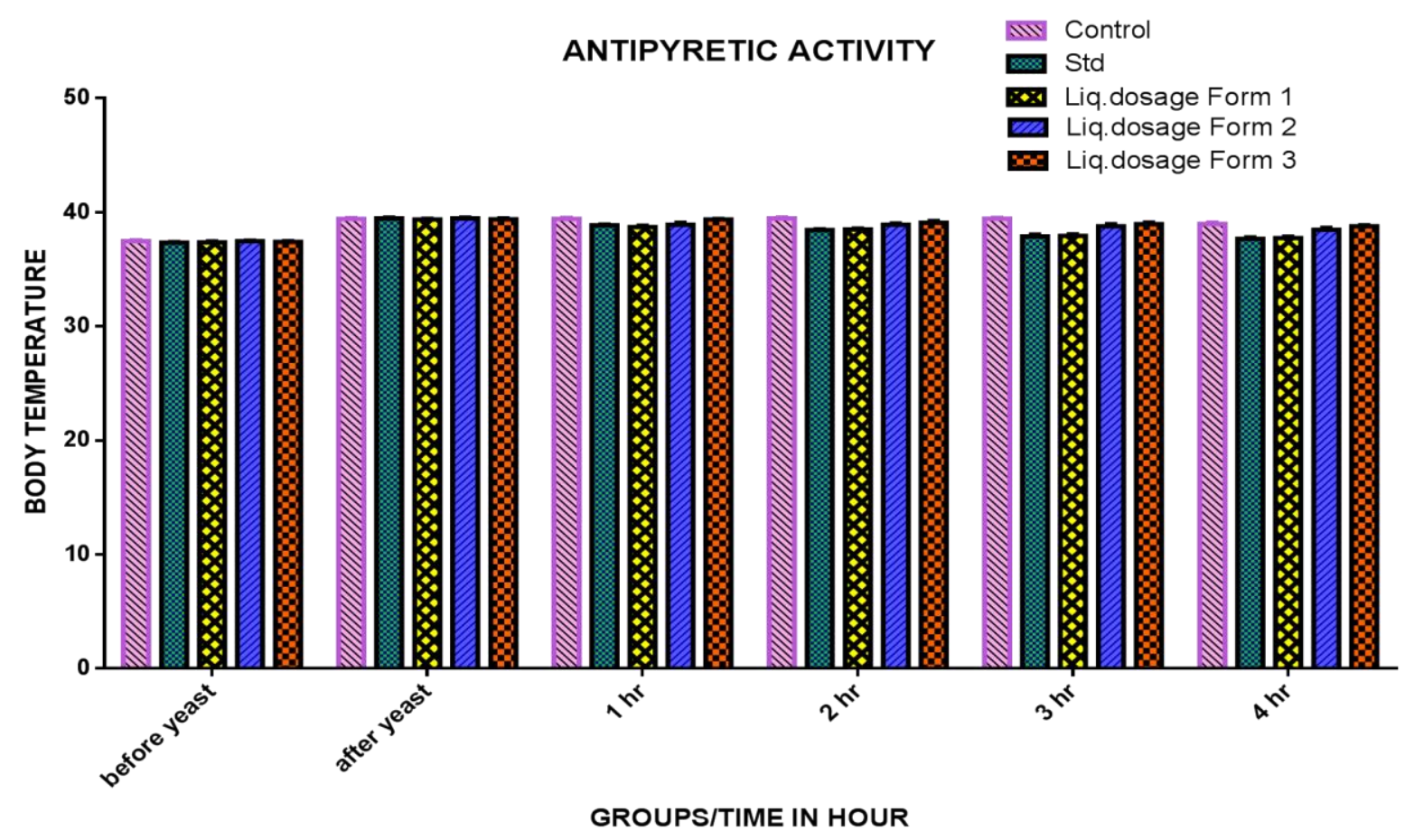

Figure 3: Antipyretic activities of liquid dosage form.

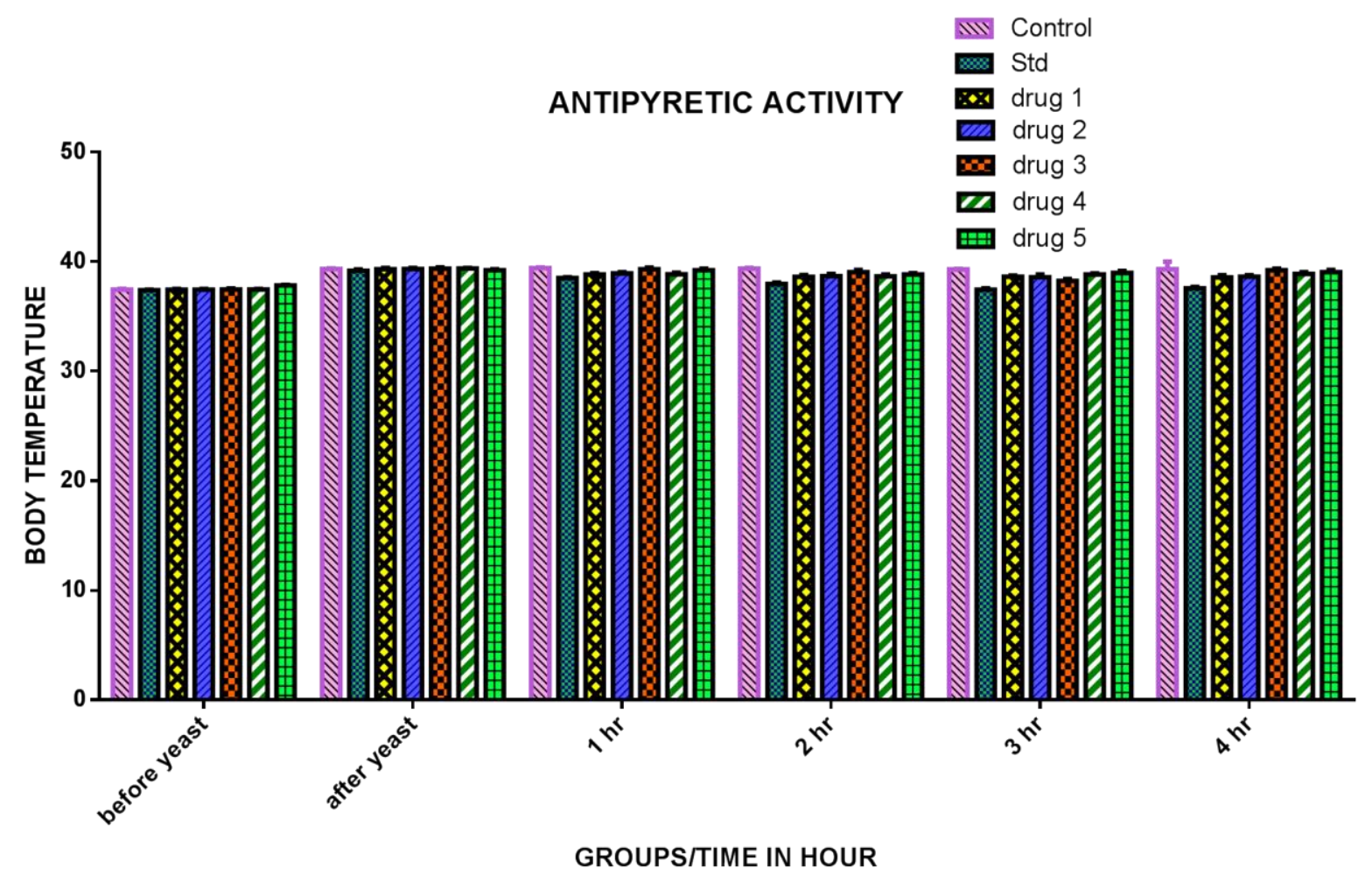

Figure 4: Antipyretic activity of individual plants. 
Table 4: Antipyretic activities of liquid dosage form.

\begin{tabular}{lllllll}
\hline Groups & Before yeast & After yeast & $\mathbf{1 ~ h r}$ & $\mathbf{2 ~ h r}$ & $\mathbf{3 ~ h r}$ & $\mathbf{4} \mathbf{~ h r}$ \\
\hline Control & $37.46 \pm 0.07$ & $39.40 \pm 0.07$ & $39.41 \pm 0.09$ & $39.45 \pm 0.07$ & $39.43 \pm 0.06$ & $38.96 \pm 0.11$ \\
Standard & $37.33 \pm 0.04$ & $39.45 \pm 0.07$ & $38.85 \pm 0.06^{* *}$ & $38.43 \pm 0.06^{* *}$ & $37.88 \pm 0.14^{* *}$ & $37.66 \pm 0.13^{* *}$ \\
LDF-1 & $37.35 \pm 0.08$ & $39.35 \pm 0.08$ & $38.71 \pm 0.10^{* *}$ & $38.48 \pm 0.09^{* *}$ & $37.91 \pm 0.14^{* *}$ & $37.71 \pm 0.12^{* *}$ \\
LDF-2 & $37.45 \pm 0.06$ & $39.45 \pm 0.06$ & $38.96 \pm 0.16^{*}$ & $38.90 \pm 0.10^{*}$ & $38.76 \pm 0.17^{*}$ & $38.46 \pm 0.16^{*}$ \\
LDF-3 & $37.38 \pm 0.07$ & $39.38 \pm 0.07$ & $39.35 \pm 0.06$ & $39.06 \pm 0.17$ & $38.93 \pm 0.16$ & $38.75 \pm 0.10$ \\
\hline
\end{tabular}

Values are mean \pm S.E.M; $\mathrm{n}=6 ;{ }^{*} \mathrm{P}<0.05$ and ${ }^{* *} \mathrm{P}<0.01$; as compared to the control; $\mathrm{LDF}=$ Liquid dosage form

Table 5: Antipyretic activity of for individual plants.

\begin{tabular}{|c|c|c|c|c|c|c|}
\hline Groups & Before yeast & After yeast & $1 \mathrm{hr}$ & $2 \mathrm{hr}$ & $3 \mathrm{hr}$ & $4 \mathrm{hr}$ \\
\hline Control & $37.45 \pm 0.06$ & $39.33 \pm 0.04$ & $39.40 \pm 0.05$ & $39.35 \pm 0.08$ & $39.28 \pm 0.06$ & $39.31 \pm 0.07$ \\
\hline Standard & $37.38 \pm 0.07$ & $39.16 \pm 0.11$ & $38.50 \pm 0.07^{* *}$ & $37.95 \pm 0.14^{* *}$ & $37.45 \pm 0.10^{* *}$ & $37.55 \pm 0.13^{* *}$ \\
\hline Plant 1 & $37.45 \pm 0.06$ & $39.31 \pm 0.11$ & $38.81 \pm 0.12^{*}$ & $38.61 \pm 0.17^{*}$ & $38.63 \pm 0.09^{*}$ & $38.56 \pm 0.18^{*}$ \\
\hline Plant 2 & $37.45 \pm 0.06$ & $39.33 \pm 0.09$ & $38.91 \pm 0.14^{*}$ & $38.68 \pm 0.19^{*}$ & $38.58 \pm 0.24^{*}$ & $38.63 \pm 0.12^{*}$ \\
\hline Plant 3 & $37.46 \pm 0.07$ & $39.35 \pm 0.13$ & $39.31 \pm 0.14$ & $39.05 \pm 0.19$ & $39.25 \pm 0.17$ & $38.21 \pm 0.15$ \\
\hline Plant 4 & $37.46 \pm 0.06$ & $39.38 \pm 0.05$ & $38.85 \pm 0.13^{*}$ & $38.66 \pm 0.17^{*}$ & $38.81 \pm 0.10$ & $38.86 \pm 0.19$ \\
\hline Plant 5 & $37.83 \pm 0.04$ & $39.20 \pm 0.10$ & $39.20 \pm 0.16$ & $38.81 \pm 0.14$ & $38.96 \pm 0.18$ & $39.63 \pm 0.19$ \\
\hline
\end{tabular}

Values are mean \pm S.E.M; $n=6 ;{ }^{*} \mathrm{P}<0.05$ and ${ }^{* *} \mathrm{P}<0.01$; as compared to the control

\section{Antipyretic activity}

PHF 1 and PHF 2 significantly $(\mathrm{P}<0.01$ and $\mathrm{P}<0.05$ respectively) decreased the elevated body temperature as compared to control group. The highest inhibition by PHF 1 was produced at $1,2,3$, and 4 hours but PHF 2 produces slightly significant $(\mathrm{P}<0.05)$ activity at the same time intervals so that the activity also is in dose dependent manner. While the individual plant extracts 1 and 2 exhibits slightly significant antipyretic activity $(\mathrm{P}<0.05)$ at $1,2,3$, and 4 hours. Plant extract 4 shows significant activity $(\mathrm{P}<0.05)$ only at 1 and 2 hours only.

The maximum antipyretic activity by paracetamol (P $<0.01$ ) as a standard drug was observed at $1,2,3$, and 4 hours. PHF 3 and individual drugs 3 and 5 did not produce any significant reduction in elevated body temperature as compared to control group. The observations are given in Table $4 \& 5$ and Figure $3 \& 4$.

\section{CONCLUSION}

The results of the present study shows that the polyherbal formulations possess significant analgesic and antipyretic activities in all the tested experimental animal models indicating inhibition of nociception and reduction in elevated body temperature. The poly-herbal formulation possesses central analgesic activity which was evaluated using hot plate method and antipyretic activity by brewer's yeast induced pyrexia model. According to the data obtained with the various doses of the polyherbal formulation, it was found that the intensity of the analgesic effect of PHF1 was similar to that of standard drug pentazocine and maximum when compared with individual plant extracts.

The analgesic effect produced by the extract may be via central mechanisms involving opioid receptor systems and regulation of body temperature requires a delicate balance between production and loss of heat, and the hypothalamus regulates the set point at which body temperature is maintained. Yeast induced fever is called pathogenic fever. Its aetiology includes production of prostaglandins, which set the thermoregulatory centre at a lower temperature (Howard, 1993). The present results show that PHF possesses a significant antipyretic effect in yeast-provoked elevation of body temperature in rats, and its effect is comparable to that of paracetamol (standard drug). So inhibition of prostaglandin synthesis could be the possible mechanism of antipyretic action as that of paracetamol (Chandrashekaran et al., 2009).
The present results show that PHF1 possesses a significant antipyretic effect in yeast induced elevation of body temperature in rats, and its effect is comparable to that of paracetamol (standard drug). So inhibition of prostaglandin synthesis could be the possible mechanism of antipyretic action as that of paracetamol.

To conclude, it can be stated that the poly-herbal formulation demonstrated potent analgesic and antipyretic effects in a dose dependent manner. This could provide a rationale for the use of this formulation in pain and fever as folk medicine.

\section{REFERENCES}

Chan, M. (2008). Address at the WHO Congress on traditional medicine, Beijing, People's Republic of China. [Link]

Chandrasekharan, N.V., Dai, H., Roos, K.L., Evanson, N.K., Tomsik, J., Elton, T.S., Simmons, D. (2002). COX-3, a cyclooxygenase-1 variant inhibited by acetaminophen and other analgesic/antipyretic drugs cloning structure and expression. Proceedings of the National Academy of science, United States of America, 99(21): 13926-13931.

Copper, J.W., and Gunn, C. (1986). Tutorial Pharmacy, CBS Publisher \& distributers, New Delhi, 6th edition, pages 251-261.

Datta, S., Gosh, A., Pal, P., Das, M., Kar, P.K. (2010). Pharmacognostical, phytochemical and biological evaluation of Cardiospermum halicacabum, International Journal of Pharmaceutical Science and Biotechnology, 1(1): 3742.

Garg, V.K., Paliwal, S.K., (2011). Anti-inflammatory activity of aqueous extract of Cynodon dactylon, International journal of pharmacology, 7(3): 370-375. [DOI]

Howard M. (1993). Fever causes and consequences. Neuroscience and Biobehavioural Reviews 1, 17(3): 237-269.

Jaijoy, K., Soonthornchareonnon, N., Panthong, A., Sireeratawong, S. (2010). Anti-inflammatory and analgesic activities of the water extract from the fruit of Phyllanthus emblica Linn., International Journal of Applied Research in Natural Products, 3(2): 28-35. [Link]

Lekshmi, U.M.D., Reddy, P.N. (2011). Preliminary studies on anti-inflammatory, antipyretic and anti-diarrhoeal properties of Evolvulus alsinodes, Turkish Journal of Biology, 35: 611-618. [DOI]

Mahesh, S., Paschapur, Swati Patil, Sachin, R., Patil, Ravi kumar, M. B., Patil (2009). Evaluation of the analgesic and antipyretic activities of ethanolic extract of male flowers (inflorescences) of Borassus flabellifer (arecaceae), International Journal of Pharmacy and Pharmaceutical Sciences, 1(2): 98-106.

Mukesh, G., (2007) Pharmaceutical suspension: A review pharmainfo.net [Link] OECD Guidelines for the Testing of Chemicals, Section 4, Health Effects. [Link]

Shivaprakash, G., Gopalakrishna, H.N., Padbidri, D.S., Sadanand, S., Sekhar, S.S., Nivedita, R.S, (2011). Evaluation of Andrographis paniculata leaves extract for analgesic activity, Journal of Pharmacy Research, 4(10): 3375-3377.

Venkatesh, P., Dinakar, A., Senthilkumar, N. (2012). Evaluation of Analgesic and Antipyretic activity of alcoholic extracts of Boerhaavia diffusa and Anisochilus carnosus, Journal of Current Pharmaceutical Research; 10(1): 15-19.

WHO, (2008). Fact sheets no 134. [Link] 